\title{
NOTA
}

\section{USO ALTERNATIVO DA GRADE ARADORA SUPERPESADA NA CORREÇÃO DA ACIDEZ DO SOLO EM PROFUNDIDADE E NA PRODUÇÃO DA AVEIA PRETA ${ }^{(1)}$}

\author{
R. M. PRADO ${ }^{(2)} \&$ C. G. ROQUE $(2)$
}

\begin{abstract}
RESUMO
A máxima eficiência da calagem depende, além da qualidade do material corretivo, de uma incorporação adequada quanto à profundidade e homogeneidade. Diante disto, objetivou-se avaliar o efeito dos modos de incorporação de calcário na produção da aveia preta e na correção da acidez no perfil do solo. Para isto, foi realizado um experimento em um Latossolo Vermelho distrófico textura argi losa, na região do Triângulo Mineiro, em Uberlândia (MG), no período de maio de 1995 a fevereiro de 1996. O delineamento experimental foi em parcelas subdivididas, com as parcelas princi pais organizadas em blocos, com três repetições. As parcelas foram constituídas pelos modos de incorporação do calcário: grade aradora pesada e grade niveladora GP + GN (14 x 34"); modo tradicional, com aração ( 4 × 26") e grade niveladora A + GN (60 x 22'); grade aradora superpesada e grade niveladora GSP + GN (14 x 34"); nas subparcelas, pelas doses de calcário dolomítico, como se segue: $\mathrm{D}_{0}=$ zero de calcário; $\mathrm{D}_{1}=$ dose para elevar $V=70 \% ; D_{2}=$ dose para elevar $V=100 \%$, que corresponderam a 0; 6,0 e 9,2 t ha-1, respectivamente. 0 modo de incorporação do calcário influiu na eficiência da calagem no perfil do solo. A gradagem pesada não foi adequada para a incorporação do calcário. $\mathbf{O}$ arado de disco mais a gradagem niveladora tiveram desempenho satisfatório, atingindo até $0,20 \mathrm{~m}$ de profundidade. A gradagem superpesada proporcionou maior uniformidade e profundidade de incorporação, com neutralização da acidez do solo até $0,30 \mathrm{~m}$ de profundidade.

Termos de indexação: modos de incorporação, calagem, profundidade, saturação por bases.
\end{abstract}

(1) Recebido para publicação em janeiro de 2001 e aprovado em agosto de 2001.

(2) Doutorando em Produção Vegetal, Faculdade de Ciências Agrárias e Veterinárias, Universidade Estadual Paulista - UNESP. Via de Acesso Prof. Paulo Donato Castellane, s/n. CEP 14870-000 J aboticabal (SP). E-mail: rmprado@fcav.unesp.br 


\title{
SUMMARY: ALTERNATIVE USE OF SUPER HEAVY HARROW PLOW FOR SOIL ACIDITY LIMING AND BLACK OAT PRODUCTION
}

\begin{abstract}
Maximum liming efficiency depends not only on the quality of the corrective material but also on appropriate incorporation according to depth and homogeneity. Based on this, this work aimed to evaluate the effect of limestone incorporation ways on the production of black oat and on the correction of acidity in soil profile An experiment was carried out in a Typic Acrustox loamy texture, in the area of the Triângulo Mineiro in Uberlândia (MG) from May 1995 to February 1996. The experiment was arranged in a randomized design subdivided plots, with the main plots organized in blocks with three repetitions. The plots were constituted by the following ways of limestone incorporation: GP + GN harrow heavy plow $(14 \times 34 ") ; A+G N P+G N$ traditional way, with plowing $(4 \times 26 ")$ and harrow leveling $\left(60 \times 22^{\prime \prime}\right) ;$ GSP + GN super heavy harrow pl ow $(14 \times 34 ")$; in the subplots, for the dol omitic li mestone doses as fol lows: I imestone $\mathrm{D}_{0}=\mathrm{zero}$; $\mathrm{D}_{1}=$ the dose to el evate base saturation $(V)=70 \% ; D_{2}=$ the dose to el evate $V=100 \%$, that corresponded to $0 ; 6.0$ and $9.2 \mathrm{t} \mathrm{ha}^{-1}$, respectively. The way limestone is incorporated affects liming efficiency in thesoil profile. Heavy harrowing was not adapted for li mestone incorporation. The disk plow combined with theharrowing had a satisfactory performance, reaching $0.20 \mathrm{~m}$ depth. The super heavy har rowing provides larger uniformity and incorporation depth, with neutralization of soil acidity up to $0.30 \mathrm{~m}$ depth.
\end{abstract}

Index terms: incorporation ways, liming, depth, basis saturation.

\section{NTRODUÇÃO}

Considerando o alto grau de intemperização, os solos tropicais normalmente apresentam baixa fertilidade natural com baixa CTC, baixo pH e alta saturação por alumínio (EMBRAPA, 1976). Por essa razão, a exploração agrícola desses solos passa obrigatoriamente pela necessidade de correção da acidez.

A questão do calcário no Brasil enfrenta vários problemas, dentre os quais se pode destacar a baixa quantidade utilizada nos solos tropicais, quando comparada à sua necessidade. No Brasil, normalmente são utilizados cerca de 20 milhões de toneladas/ano de cal cário, para uma capacidade de moagem de 50 milhões de toneladas/ano. Com a subutilização, a relação média cal cário/aduboébaixa (cerca de 1:1) comparada com o que é recomendado pela FAO, cerca de 4:1 para solos tropicais (Lopes, 1994). Além da pequena quantidade de calcário usado, existe outro problema, o manejo inadequado do produto, ou seja, a dose de cal cário cal culada para incorporação entre 0,0 e 0,20 m de profundidade é incorporada em profundidade menor em razão do uso de grades aradoras intermediárias ou niveladoras. I sso se reflete negativamente nas propriedades físicas dos solos, causando sua degradação e erosão (Freitas, 1992), além de reduzir a disponibilidade de mi cronutrientes e, conseqüentemente, a produção das culturas.
O problema da supercalagem foi evidenciado por Denardin (1984) que relatou os efeitos da grade aradora pesada na incorporação do cal cário (baseado na dose calculada para camada de 0-0,25 m) e em alguns atributos quími cos de um $L$ atossol oVermel ho do cerrado. O autor observou que, na camada abaixo de $0,15 \mathrm{~m}$, onde os teores de $\mathrm{Ca}^{2+}+\mathrm{Mg}^{2+}$ eram baixos e ocorriam al tos teores de alumínio $\left(20 \mathrm{mmol}_{\mathrm{C}} \mathrm{dm}^{-3}\right)$, houve restrição ao crescimento de raízes, expondo as culturas à erosão e tornando-as mais sujeitas aos veranicos.

É sabido que o cal cário, em geral, apresenta baixa solubilidade, razão por que requer adequado contato com as partículas de solo para reagir. Portanto, a incorporação ao solo é fundamental para a reação do calcário e, de modo geral, os agricultores negligenciam sua importância, o que resulta em menor eficiência da calagem na correção da acidez do solo (Quaggio, 2000). SegundoAndrade (1991), a eficiência da calagem envolve diversos fatores, tais como; a quantidade, qualidade, profundidade de incorporação e intervalo entre aplicações. Destes aspectos, o autor afirma ser a profundidade de incorporação a mais importante.

As informações quanto à eficiência do equipamento na incorporação de corretivos a profundidades maiores e com homogeneidade adequada são insuficientes. No Brasil, a incorporação de calcário éfeita invariavel mente com grades intermediárias ou até niveladoras. Assim, 
os arados estão perdendo espaço para as grades, em virtude de seu alto custo operacional (Dallmeyer, 1986).

Com relação à profundidade de incorporação, observa-se que as culturas apresentam respostas diferenciadas quanto à produção. A incorporação do calcário (aração com aiveca e gradagem niveladora), em maiores profundidades, até 0,30 m, apresenta maior eficiência, com respostas positivas na produção de milho (Gonzales-É rico et al., 1979; Alonço \& Ferreira, 1992), especialmente quando ocorrerem veranicos (Dedecek et al., 1986) e até ausência de resposta em culturas do milho (média de três híbridos) e soja (Sá, 1993). Canalli \& Roloff (1997) acrescentam quea aração profunda não traz benefício adicional ao solo, além de promover a mistura de horizontes, em solos rasos, e consumir mais energia e cal cário.

Cabe destacar, ainda, queexistem diversos fatores que afetam a profundidade da aração, além do tipo de equipamento utilizado, tais como: o peso total e o ângulo horizontal de ataque do implemento (Folle et al., 1992), o tipo de corpo ativo, ou seja, arado de discos ou de aivecas (Gabriel Filho, 1998) e o tipo de disco, ou seja, centro convexo de bordo liso ou recortado e centro côncavo (Batista, 1987).

O trabalho objetivou avaliar o efeito dos modos de incorporação de cal cário com gradagem pesada + gradagem niveladora, aração + gradagem niveladora e gradagem superpesada + gradagem niveladora na produção da aveia preta e na correção da acidez no perfil do solo.

\section{MATERIAL E MÉTODOS}

O experimento foi realizadona Fazenda Beija-Flor, no município de Uberlândia (MG), no período de maio de 1995 a fevereiro de 1996. Segundo a classificação de Köppen, o clima local é do tipo Cwa, subtropical com inverno curto, moderado e seco, e verão quente e chuvoso, caracterizando duas estações distintas.

Utilizou-se um LatossoloVermel ho distrófico, com textura argilosa nas camadas de 0-0,20 m e 0,20$0,30 \mathrm{~m}$, ou seja, 410 e $425 \mathrm{~g} \mathrm{~kg}^{-1}$ deargila, respectivamente. $A$ área em questão permaneceu sob plantio de eucal ipto por mais de 10 anos; após esse período, realizou-se um cultivo com arroz de sequeiro com preparo convencional e, no ano agrícola seguinte (95/ 96), introduziu-se o experimento.

Antes da instalação do experimento, foram coletadas 20 subamostras desolo, na área $\left(4.320 \mathrm{~m}^{2}\right)$, por profundidade, para compor a amostra composta, nas camadas de $0-0,10 ; 0,10-0,20$ e 0,20-0,30 m. Os resultados das análises químicas para fins de fertilidade encontram-se no quadro 1.

O delineamento experimental foi parcelas subdivididas, com as parcel as princi pais organizadas em blocos com três repetições. Os tratamentos principais, parcelas, foram constituídos pel os modos de incorporação do cal cário, sendo (a) metade da dose distribuída a lanço e, em seguida, incorporada com grade aradora pesada (GP + GN) com controle remoto (discos com 14 x 34", espaçados de 340 mm, com peso total de $2.932 \mathrm{~kg}$ e largura de corte $2.210 \mathrm{~mm}$ ) tracionada por trator de pneu $4 \times 4 \mathrm{com}$ $146 \mathrm{cv}$ e metade da dose, também a Ianço, incorporada com grade niveladora (discos de 60 x 22"); (b) metade da dose distribuída a lanço, incorporada com aração com arado de discos lisos $(A+G N)$ (discos de $\left.4 \times 26^{\prime \prime}\right)$ e metade da dose também distribuída a lanço, incorporada com grade niveladora (discos de $60 \times 22$ "); (c) dose inteira do calcário aplicado a lanço e, em seguida, incor porada com grade aradora superpesada (GSP + GN) com controle remoto (discos de $14 \times 34 ")$, espaçados de $440 \mathrm{~mm}$, com peso total de $3.814 \mathrm{~kg}$ elargura de corte $2.650 \mathrm{~mm}$ ) tracionada por trator de esteira com 140 cv e com grade niveladora (discos de 60 × 22").

Nas subparcelas, os tratamentos secundários constituíram-se de doses de calcário dolomítico (PRNT = 64,0\%; RE = 87,3\%; PN = 73,3\%; $\mathrm{CaO}=$ $37,2 \%$ e $M g O=27,0 \%$, como se segue: $D_{0}=$ zero de calcário; $\mathrm{D}_{1}=$ dose para el evar $\mathrm{V}$ a $70 \% ; \mathrm{D}_{2}=$ dose para el evar $\vee$ a $100 \%$, as quais corresponderam a 0; 6,0 e 9,2 t ha-1 de cal cário, respectivamente. A incorporação do cal cário ocorreu em maio de 1995.

As parcelas experimentais foram compostas por 40 linhas de aveia preta (Avena strigosa Schieb) cv. IAPAR 61, espaçadas de 0,2 m entrelinhas, com densidade populacional inicial de 50 plantas por metro linear, porém foram consideradas apenas as trinta linhas centrais como úteis para as aval iações.

Quadro 1. Propriedades químicas do solo da área experimental anterior à instalação do experimento

\begin{tabular}{|c|c|c|c|c|c|c|c|c|c|c|}
\hline Camada & $\mathrm{pH} \mathrm{CaCl}_{2}$ & M.O. & P resina & $\mathbf{K}^{+}$ & $\mathrm{Ca}^{2+}$ & $\mathbf{M g}^{2+}$ & $\mathbf{H}+\mathbf{A l}$ & SB & $\mathbf{T}$ & $\mathbf{v}$ \\
\hline $\mathrm{m}$ & & $\mathrm{g} \mathrm{dm}^{-3}$ & $\mathrm{mg} \mathrm{dm}{ }^{-3}$ & 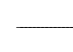 & . & $\mathrm{mr}$ & $\mathrm{dm}^{-3}$ & & - & $\%$ \\
\hline $0-0,10$ & 4,3 & 17 & 5 & 0,6 & 9 & 1 & 59 & 10,6 & 69,6 & 15 \\
\hline $0,10-0,20$ & 4,1 & 16 & 3 & 0,4 & 8 & 1 & 57 & 9,4 & 66,4 & 14 \\
\hline $0,30-0,40$ & 4,0 & 15 & 3 & 0,3 & 5 & 1 & 58 & 6,3 & 64,3 & 10 \\
\hline
\end{tabular}


A semeadura da aveia preta foi realizada em 1-1095, cinco meses após a incorporação do cal cário ao solo. Cabe destacar que a escol ha da aveia preta se deu pela sua importante área cultivada atual mente no Cerrado e pela falta de informações quanto à sua resposta à calagem, na região. Além disto, objetivouse também a formação de cobertura morta no solo, servindo de suporte para instalação do sistema plantio direto nos cultivos subseqüentes.

A adubação básica na semeadura constou da aplicação de $300 \mathrm{~kg} \mathrm{ha}^{-1}$ da fórmula 4-20-20 + 0,3\% Zn e, em cobertura, 30 dias após a emergência, $60 \mathrm{~kg} \mathrm{ha}^{-1}$ de $\mathrm{N}$ na forma de uréia.

Aos 110 dias da semeadura, realizou-sea col heita dos grãos da aveia. Nesta mesma época, realizaramse as amostragens de solo, nas profundidades de 0 $0,10,0,10-0,20$ e 0,20-0,30 m, a fim de avaliar os efeitos da calagem ao longo do perfil do solo. Foram coletadas 20 subamostras por parcela, nas entrelinhas da cultura, a fim de constituir uma amostra composta. As determinações analíticas no solo seguiram os métodos descritos por Raij et al. (1987).

Os dados foram submetidos à análise de variância. As médias dos resultados foram comparadas pel oteste deTukey $(\mathrm{P}<0,05)$, bem como realizado um estudo de regressão polinomial simples. Foi utilizado o programa SANEST-PC (Zonta et al., 1982).

\section{RESULTADOS E DISCUSSÃO}

Houve efeito significativo dos modos de incorporação do calcário na produção de grãos da aveia preta (Figura 1). Observou-se que o modo de incor poração al ternativa de cal cário com gradagem superpesada (GSP + GN) foi semelhante ao modo convencional de aração seguida de gradagem niveladora $(A+G N)$, porém superior à gradagem pesada $(G P+G N)$. Acrescenta-se queo convencional foi semelhante ao da gradagem pesada, o que concorda com Oliveira et al. (1996) e Weirich N eto et al. (2000) que observaram terem sido estas duas formas de incorporação semel hantes na produção do milho.

No entanto, outros autores relataram que a prática de incorporação convencional de aração, seguida de gradagem, foi superior ao da gradagem pesada (Gonzales-Érico et al., 1979; Alonço \& Ferreira, 1992). Esta divergência de resultados quanto ao modo convencional e da gradagem na produção das culturas depende fundamentalmente do grau de acidez subsuperficial e da tolerância da planta à acidez do solo, bem como da quantidade e das características do corretivo usado, com diferentes granulometrias e tempo de reatividade. Como o modo al ternativo de incorporação do cal cário, a grade

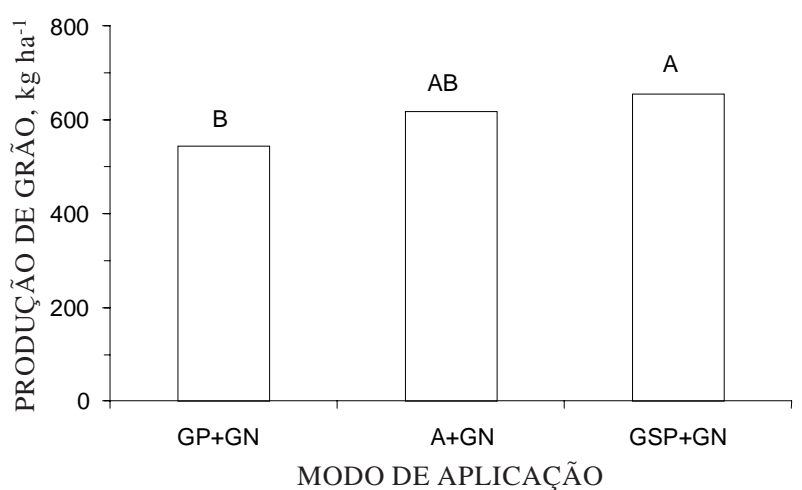

Figura 1. Efeito dos modos de incorporação de calcário por meio da gradagem pesada $(G P+G N)$, aração $(A+G N)$ e da gradagem superpesada (GSP + GN) na produção de grãos da cultura da aveia preta (GN =grade niveladora). (Média para todas as doses de calcário).

superpesada mostrou-se promissora quanto à produção da aveia preta, pois poderia substituir o modo convencional por apenas uma operação.

A aplicação do cal cário al terou significativamente a correção da acidez no perfil do solo de forma distinta, conforme o modo de incorporação (Quadro 2). Os modos de incorporação foram semelhantes para a camada superficial do solo (0$0,10 \mathrm{~m})$, com vantagem para a gradagem pesada, especialmente no aumento da saturação por bases. $\mathrm{Na}$ camada de 0,10-0,20 m, os modos de incorporação com aração e de gradagem superpesada foram superiores à gradagem pesada, enquanto para a camada mais profunda $(0,20-0,30 \mathrm{~m})$, destacou-se a gradagem superpesada na neutralização da acidez do solo. Portanto, estes resultados indicam que os efeitos benéficos do cal cário foram detectados até à camada de 0,10 m, quando o modo de incorporação do calcário foi a gradagem pesada; até $0,20 \mathrm{~m}$, quando o calcário foi incorporado com aração ou gradagem superpesada, e até $0,30 \mathrm{~m}$, somente com incorporação com gradagem superpesada.

Ressalta-se que os teores de $\mathrm{Ca}^{2+}+\mathrm{Mg}^{2+}$, pela incorporação rasa do calcário (gradagem pesada) incrementaram em 20\%, ou seja, 23 para $28 \mathrm{mmol}_{\mathrm{c}} \mathrm{dm}^{-3}$, em relação à incorporação profunda (gradagem superpesada) (Quadro 2), ao passo que Dedecek et al. (1986) observaram, em sistemas de incorporação semelhante, um incremento maior, atingindo $37 \%$ destes nutrientes na camada superficial do solo. Este incremento nos teores de bases, do valor $\mathrm{pH}$ e da saturação por bases na camada superficial do solo $(0-0,10 \mathrm{~cm})$, advindo de incorporação rasa do cal cário, também foi observado por Denardin (1984) e Dallmeyer (1986), podendo reduzir significativamente a disponibilidade de micronutrientes do solo, fato amplamente discutido na literatura (Malavolta, 1980). Cabe destacar que 
Quadro 2. Efeito dos modos de incorporação de calcário no valor $\mathrm{pH}$, nos teores de $\mathrm{Ca}^{2+}+\mathrm{Mg}^{2+}$ e na saturação por bases do solo, nas camadas de 0,0-0,10; 0,10-0,20 e 0,20-0,30 m de profundidade. (Média para todas as doses de calcário)

\begin{tabular}{|c|c|c|c|}
\hline \multirow{2}{*}{ Atributo químico } & \multicolumn{3}{|c|}{ Modo de incorporação } \\
\hline & Gradagem pesada (GP + GN) & Aração (A + GN) & Gradagem superpesada $($ GSP + GN) \\
\hline & \multicolumn{3}{|c|}{ Camada de $0,0-0,10 \mathrm{~m}$} \\
\hline $\begin{array}{l}\mathrm{pH} \\
\mathrm{Ca}^{2+}+\mathrm{Mg}^{2+}\left(\mathrm{mmol}_{\mathrm{c}} \mathrm{dm}^{-3}\right) \\
\mathrm{V} \%\end{array}$ & $\begin{array}{l}5,6 \mathrm{~A}^{(1)} \\
28 \mathrm{~A} \\
54 \mathrm{~A}\end{array}$ & $\begin{array}{l}5,2 \mathrm{~A} \\
24 \mathrm{~A} \\
44 \mathrm{~B}\end{array}$ & $\begin{array}{l}5,2 \mathrm{~A} \\
23 \mathrm{~A} \\
44 \mathrm{~B}\end{array}$ \\
\hline V\% & \multicolumn{3}{|c|}{ Camada de $0,10-0,20 \mathrm{~m}$} \\
\hline $\begin{array}{l}\mathrm{pH} \\
\mathrm{Ca}^{2+}+\mathrm{Mg}^{2+}\left(\mathrm{mmol}_{\mathrm{c}} \mathrm{dm}^{-3}\right) \\
\mathrm{V} \%\end{array}$ & $\begin{array}{l}4,4 \mathrm{~B} \\
13 \mathrm{~B} \\
12 \mathrm{~B}\end{array}$ & $\begin{array}{l}5,3 A \\
24 A \\
43 A\end{array}$ & $\begin{array}{l}5,4 \mathrm{~A} \\
23 \mathrm{~A} \\
44 \mathrm{~A}\end{array}$ \\
\hline $\mathrm{V} \%$ & \multicolumn{3}{|c|}{ Camada de $0,20-0,30 \mathrm{~m}$} \\
\hline $\begin{array}{l}\mathrm{pH} \\
\mathrm{Ca}^{2+}+\mathrm{Mg}^{2+}\left(\mathrm{mmol}_{\mathrm{c}} \mathrm{dm}^{-3}\right) \\
\text { V\% }\end{array}$ & $\begin{array}{l}4,3 \mathrm{~B} \\
13 \mathrm{~B} \\
8 \mathrm{~B}\end{array}$ & $\begin{array}{l}4,6 \mathrm{~B} \\
15 \mathrm{~B} \\
11 \mathrm{~B}\end{array}$ & $\begin{array}{l}5,2 \mathrm{~A} \\
23 \mathrm{~A} \\
36 \mathrm{~A}\end{array}$ \\
\hline
\end{tabular}

(1) Letras iguais, na mesma linha, não diferem entre si pelo teste de Tukey $(P<0,05)$.

as demais propriedades químicas do solo, comoteores de K, P, MO e CTC (dados não apresentados), não foram afetados pel os tratamentos.

Deste modo, a incorporação convencional do calcário com arado e grade pesada acarretou a neutralização da acidez em maiores profundidades (Quadro 2). Tais resultados também foram relatados por Maia et al. (1996) que observaram melhor distribuição do calcário no perfil do solo realizado pelos arados de discos, quando comparados com grade pesada. Acrescenta-se, ainda, que a superioridade da grade superpesada para atingir maiores profundidades de correção da acidez do solo mostra-se promissora, tendo em vista a redução do número de operações, além degarantir maior contato corretivo-solo no perfil do solo, com ganhos na vel ocidade de reação do material corretivo, uma vez que o sistema de rotação dos discos mistura eficientemente o cal cário.

Independentemente do modo de incorporação, a calagem incrementou a produção de aveia preta (Figura 2). Este efeito da calagem na produção da aveia foi quadrático, visto que $90 \%$ da produção máxima esteve associada com 5 t ha-1 de calcário. Tais resultados corroboram os de Hernani et al. (1995) que relataram resposta favorável da aveia preta à correção da acidez do solo, enquanto Pöttker \& Ben (1998) não observaram resposta na produção da aveia preta (cv. UPF 14) em detrimento do efeito residual do calcário (após dois anos da aplicação) em sistema plantio direto. Estas diferenças entre os autores podem ser atribuídas às condições climáticas das áreas experimentais e, principal mente, ao uso de cultivares distintos.
O efeito benéfico de neutral ização da acidez pela incorporação do calcário com grade super pesada na camada subsuperficial do solo pode explicar o efeito superior deste modo de incorporação na produção de grãos da aveia (Figura 2). Esses efeitos dos tratamentos na produção da aveia preta ainda não foram maiores por ser o crescimento do sistema radicular desta cultura superficial, característica comum nas gramíneas.

É importanterelatar que, independentemente do modo de incorporação do cal cário, a saturação por bases cal culada não foi atingida (Figura 3). Estefato érelatado na literatura, sendo atribuído às taxas de reatividade do calcário, que a legislação vigente superestima, considerando período detrês meses em condições de campo, atingindo a reatividade

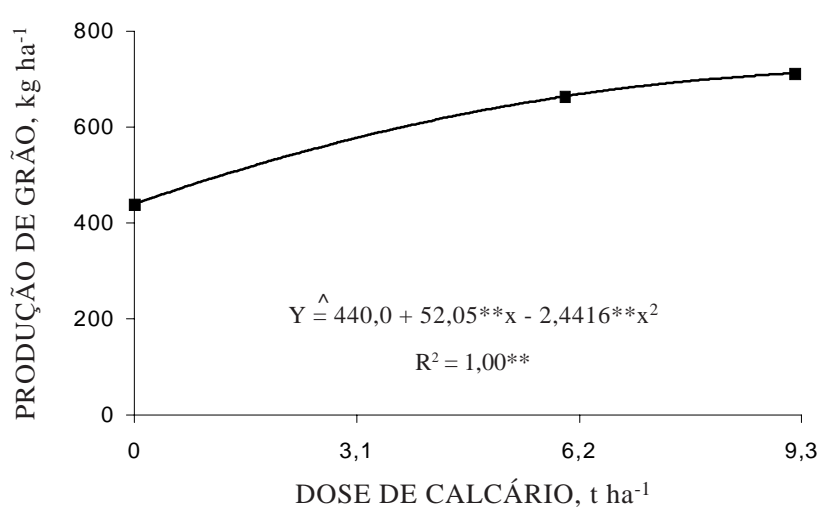

Figura 2. Efeito da aplicação de calcário na produção de grãos da aveia preta. Significativo a 1\% (Média para todas as doses de calcário). 
preconizada apenas 18 meses após a incorporação do calcário no solo (Natale \& Coutinho, 1994). Segundo outros autores, a máxima reação do cal cário no solo em condições de campo ocorre somente entre período de 18 a 33 meses após a sua incorporação ao solo (Quaggio et al., 1982; Oliveira et al., 1997). Além disso, com doses maiores de calcário, ocorre desl ocamento da reação de equilíbrio de sol ubi lização do corretivo, bem como a formação de novos minerais no solo em formas de hidróxido pouco solúvel (Tescaro, 1998). Observam-se, ainda, pelo grau de mistura com as partículas de solo, uma vez que as operações de incorporação de campo são heterogêneas, pequenas zonas ao redor das partículas, excessivamente corrigidas, separadas por espaços sem nenhuma correção (Quaggio, 2000).

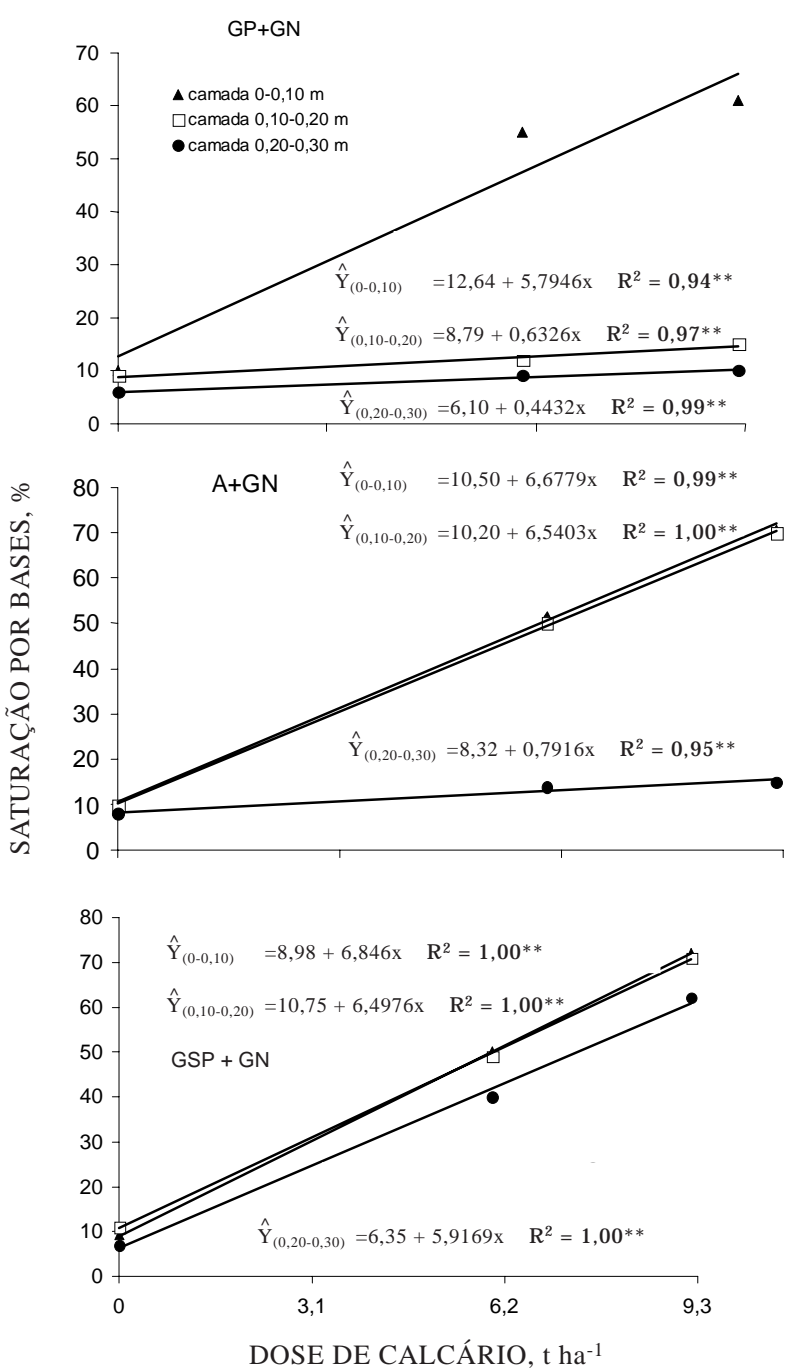

Figura 3. Efeito dos modos de incorporação do calcário por meio da gradagem pesada $(\mathrm{GP}+\mathrm{GN})$, aração $(A+G N)$ e da gradagem superpesada (GSP +GN), considerando diferentes doses de corretivo e profundidades sobrea saturação por bases do solo (GN =grade niveladora).
Dentre as diversas hipóteses que explicam a dificuldade de atingir a saturação por bases pretendida, a que exprime a dificuldade de mistura do material corretivo ao solo pode ser a mais promissora, considerando os efeitos diferenciados dos modos de incorporação na correção da acidez do sol o. A grade superpesada foi a que mais se aproximou da saturação por bases calculada, nas três camadas de solo analisadas (Figura 3), caracterizando maior homogeneidade de incorporação das partículas de calcário e a massa de solo, embora seja dificil encontrar, em condições de campo, o mesmo grau de mistura conseguida em pequenas porções de solo.

\section{CONCLUSÕES}

1. O modo de incorporação do calcário afetou a eficiência da calagem no perfil do solo.

2. A gradagem pesada não foi adequada para a incorporação do cal cário, ao passo que oarado de disco mais a gradagem niveladora tiveram desempenho satisfatório, atingindo até $0,20 \mathrm{~m}$ de profundidade, e a gradagem superpesada proporcionou maior uniformidadee profundi dade de incorporação, com neutral ização da acidez do solo até $0,30 \mathrm{~m}$ de profundidade.

\section{AGRADECIMENTOS}

À Fazenda Beija-Flor, por ceder a área experimental e pel o financiamento da pesquisa, e ao $\mathrm{Eng}^{\circ} \mathrm{Agr}$ 은 J osé Hortêncio M ota, pelos trabal hos de campo.

\section{LITE RATURA CITADA}

ALONÇO,A.S. \& FERREIRA, O.O. Incorporação profunda de fertilizantes e cal cário: sua influência na produção de milho (Zea mays L.) sob estresse hídrico e, sobre algumas propriedades físicas e químicas de um solo de cerrado. In: CONGRESSO BRASILEIRO DE ENGENHARIA AGRÍ COLA, 20., Londrina, 1991. Anais. Londrina, Instituto Agronômico do Paraná, 1992. p.57.

ANDRADE, L.A.B. Calagem para a cultura da cana-de-açúcar. Inf. Agropec., 15:15-16, 1991.

BATISTA, J .M. I nfluência da forma geométrica dos discos dearado no preparo do solo de cerrado. In: CONGRESSO BRASI LEIRO DE ENGENHARIA AGRÍ COLA, 16.,J undiai, 1987. Anais. Campinas, InstitutoAgronômico de Campinas, 1987. p.29.

CANALLI, L.B. \& ROLOFF, G. I nfluência do preparo e da correção do solo na condição hídrica de um Latossolo VermelhoEscuro sob plantio direto. R. Bras. Ci. Solo, 21:99-104, 1997.

DALLMEYER, A.V. As máquinas utilizadas na distribuição e incorporação de calcário. In: SIMPÓSIO SOBRE APLICAÇÃO APLICAÇÃO DE CALCÁRIO NA AGRICULTURA, 1., Campinas, 1986. Anais. Campinas, Fundação Cargill, 1986. p.23-29. 
DEDECEK, R.A.; PEREIRA, J .; IKE, M. \& IWATA, F. Efeito de profundidade dearação inicial, modos deadubação corretiva e sistemas de preparo do sol o na produção de soja em solo de cerrados. R. Bras. Ci. Solo, 10:173-80, 1986.

DENARDIN, J.E. Manejo adequado do solo para áreas motomecanizadas. In:SIMPÓSIO DE MANEJ O DO SOLO E PLANTIO DIRETO NO SUL DO BRASIL, 1., PaSSO Fundo, 1984. Anais. Passo Fundo, Empresa Brasileira de Pesquisa Agropecuária, 1984, p.107-23.

EMPRESA BRASILEIRA DE PESQUISA AGROPECUÁRIA EMBRAPA. Centro Nacional dePesquisas Agropecuária do Cerrado. Relatório técnico anual 1975-76. Brasília,1976. $154 p$.

FOLLE, S.M.; FRANZ, C.A.B. \& ALONÇO, A.S. Influência do ângulo horizontal no desempenho de arado de disco. In: CONGRESSO BRASILEIRO DE ENGENHARIA AGRÍ COLA, 20., Londrina, 1991. Anais. Londrina, Instituto Agronômico do Paraná, 1992. p.59.

FREITAS, P.L. Manejo físico do solo. In: SIMPÓSIO SOBRE MANEJ O E CONSERVAÇÃO DO SOLO NO CERRADO, 1., Goiânia, 1992. Anais. Goiânia, Fundação Cargill, 1992. p.117-39.

GABRIEL FILHO,A. Avaliação de cinco formas geométricas de corpos de arados no preparo de dois tipos de solos e do comportamento da cultura do milho (Zea mays L). Botucatu, Faculdade de Ciências Agronômicas, Universidade Estadual Paulista, 1998. 134p. (Tese de Doutorado)

GONZALES-ÉRICO, E.; KAMPRATH, E.J .; NARDERMAN J ÚNIOR, G.C. \& SOARES, W.V. Effect of deph of lime incorporation on the growth of corn on na Oxisol of Central Brasil. Soil Sci. Soc. Am. J., 43:1155-1158, 1979.

HERNANI, L.C.; ENDRES, V.C.; PITOL, C. \& SALTON, J.C. Adubos verdes de outono/inverno no Mato Grosso do Sul. Dourados, Empresa Brasileira de Pesquisa Agropecuária, 1995. 93p. (EMBRAPA-CPAO, Documentos, 4)

LOPES,A.S. Uso de tecnol ogia moderna na preservação do meio Ambiente. In: SIMPÓSIO NACIONAL DO SETOR DE FERTILIZANTES, 1., São Paulo, 1997, Anais. São Paulo, ANDA,IBRAFOS, 1994. p.247-80.

MAIA, J.C.S.; WEBER, O.L.S.; SGUAREZZI, J J .; AGUILLERA, L.A. BOTTAN, A.J .; PEREIRA, L.C. \& BEZERRA, E.L. Influência de diferentes sistemas de incorporação de calcário sobre as propriedades químicas de um Latossolo Vermelho-Amarelo, em região de Cerrados MatoGrossenses. Agron. Trop., 1:41-49,1996.
MALAVOLTA, E. Elementos de nutrição mineral de plantas. São Paulo, Agronômica Ceres, 1980. 251p.

NATALE, W. \& COUTINHO, E.L.M. Avaliação da eficiência agronômica de diferentes frações granulométricas de um calcário dolomítico. R. Bras. Ci. Solo, 18:55-62, 1994.

OLIVEIRA, I.P.; KLUTHCOUSKI,J .;YOKOYAMA, L.P.; DUTRA, L.G.; PORTES, T.A.; SILVA, A.E.; PINHEIRO, B.S.; FERREIRA, E. \& CASTRO, E.M. Sistema Barreirão: Recuperação/Renovação de pastagens degradadas em consórcio com culturas anuais. Goiânia, Empresa Brasileira de Pesquisa Agropecuária, 1996. 90p. (EMBRAPA-CNPAF. Documentos, 64)

OLIVEIRA, E.L.; PARRA, M.S. \& COSTA,A. Resposta da cultura do milho, em um Latossolo Vermelho-Escuro álico, à calagem. R. Bras. Ci. Solo, 21:65-70, 1997.

PÖTTKER, D. \& BEN, J.R. Calagem para uma rotação de culturas no sistema de plantio direto. R. Bras. Ci. Solo, 22:675-684, 1998.

QUAGGIO, J.A.; MASCARENHAS, H.A.A.\& BATAGLIA, O.C. Resposta da soja à aplicação de doses crescentes de cal cário em L atossol o Roxo distrófico do cerrado. II. Efeito residual . R. Bras. Ci. Solo, 6:113-118, 1982.

QUAGGIO,J .A. A acidez ecalagem em solos tropicais. Campinas, Instituto Agronômico de Campinas, 2000. 111p.

RAIJ, B.van; QUAGGIO, J.A. \& CANTARELLA, H. Análise química do solo para fins de fertilidade. Campinas, Fundação Cargill, 1987. 107p.

SÁ, J.C.M. Manejo da fertilidade do solo no sistema de plantio direto. In: PLANTIO direto no Brasil. Passo Fundo, Empresa Brasileira de Pesquisa Agropecuária, 1993. p.3759.

TESCARO, M.D. Eficiência do método da saturação de bases para a correção da acidez de um solo álico. In: REUNIÃO BRASILEIRA DE FERTILIDADE DO SOLOE NUTRIÇÃO DE PLANTAS, 23., Caxambu, 1998, Resumos. Lavras, Universidade Federal de Lavras, 1998. p.103.

ZONTA, E.P.; MACHADO, A.A. \& SILVEIRA J ÚNIOR, P. Sistema de análise estatística - SANEST. Pelotas, 1982. Registro SEI № 066060.

WEIRICH NETO, P.H.; CAIRES, E.F.; J USTINO, A. \& DIAS, J. Correção da acidez do solo em função de modos de incorporação de calcário. Ci. Rural, 30:257-261, 2000. 
